\title{
Single best answer MCQs in anaesthesia: volume I clinical anaesthesia
}

\author{
Cyprian Mendonca, Mahesh Chaudhari, Biju Kurian, Josephine James. TFM Publishing. \\ 2010, 198 pages, \$59.95 USD. ISBN 978-903378-75-5
}

\author{
Amy Fraser
}

Published online: 3 February 2011

(C) Canadian Anesthesiologists' Society 2011

This compact tome - sized just small enough to fit into the pocket of scrub pants - is yet another preparatory book aimed directly at the anxious hearts and vulnerable wallets of those about to take their anesthesia certification exams.

Perhaps knowing that this book from the United Kingdom would join the ranks of other, better-known, and mostly American-produced exam-prep manuals, the editors aimed for a niche within this little market: specifically, Single Best Answer MCQs in Anaesthesia is intended to address the increasingly popular trend of constructing multiple choice questions (MCQs) as exercises in clinical reasoning. For the purposes of this review, this book is compared with two of the above-mentioned American manuals: Hall and Chantigian's Anesthesia: A Comprehensive Review, $4^{\text {th }}$ Edition, 2010, and Chu's Clinical Anesthesiology Board Review: A Test Simulation and SelfAssessment Tool, 2005.

The book includes 150 MCQs, each of which has a clinically-based stem and five distractors. The book is divided into five sections of 30 questions, and each section is followed by an answer code. Every answer includes a detailed explanation of the clinical reasoning and is accompanied by one or two recent references. The content of the questions is almost always current, correct, and relevant.

This volume has a few important strengths. First, the questions are very likely newer than those in other MCQtype review books (for example, Clinical Anesthesia Board Review contains the American Board of Anesthesiology (ABA) exam questions from the early 1990s, while the 2010 edition of Anesthesia: A Comprehensive Review

\footnotetext{
A. Fraser $(\bowtie)$

The Ottawa Hospital, Ottawa, ON, Canada
}

retains many of the same questions as its 2002 edition). All of the questions in Single Best Answer MCQs are based on clinical reasoning, whereas the other two manuals include only a small percentage of this type of question. The questions cover a fairly reasonable spectrum of North American anesthesia practice, although the authors tend to favour the content areas of resuscitation and management of medical comorbidities. The degree of difficulty of the questions is variable; most items target residents' knowledge levels from postgraduate year 3 (PGY-3) to PGY-5.

Several caveats should be considered before paying $\$ 60$ to buy this book. First, owing to its British roots, the Canadian reader will encounter unfamiliar terminology, medication names, acronyms, guidelines, and measurement units throughout the text. Second, unlike its competitors, this book does not reference the major anesthesia textbooks (e.g., Miller's Anesthesia, Barash's Clinical Anesthesia, and Stoelting's Anesthesia and Co-existing Disease), but instead it references scientific articles. This referencing approach to source documents allows the tome to be as current as possible, but it also means that some older, smaller, and lesser-known studies are used to support questions about some rather esoteric topics. And third, Canadian anesthesia practitioners might legitimately consider some of the content to be the territory of other specialties, for example, ultrasound findings in acute pancreatitis or classification of postpartum suicide. Perhaps there is also some overemphasis on relatively rare diseases, such as Guillain-Barré syndrome, which merited two questions from the first 60 questions in the book.

This education enthusiast has some additional comments regarding the questions themselves. While most questions are well-written, some use a "clinical" example whose only function is to disguise a question that tests knowledge recall. In the majority of cases, questions would benefit 
from a reduction in the number of distractors from five to four. In order to have the best quality of question stems and distractors in the next edition, this book would also benefit from the application of Haladyna and Downing's classic multiple choice item writing guidelines (1989; update 2002) (Haladyna TM, Downing SM, Rodriguez MC. A review of multiple-choice item-writing guidelines for classroom assessment. Applied Measurement in Education 2002; 15: 309-34).

Finally, cost-effectiveness should always be considered when making textbook purchases. The cost per question of this book - $\$ 60$ for 150 questions - is substantially higher than the two books that were used for comparison $(\$ 90$ for 1,000 questions in Anesthesia: A Comprehensive Review, and $\$ 80$ for 350 real, if stale-dated, ABA exam items in Clinical Anesthesia Board Review). It might be worth the price if you consider the novelty of the content and the desirability of the question structure.

In summary, this book would make a nice addition to a departmental anesthesia library, where it would become instantly popular with PGY-5s. Undoubtedly, when residents bring the book to the operating room, staff anesthesiologists will want to take a peek at it too, just to ensure that they can still recall their way through the treatment of thiocyanate poisoning. However, this book has limited value as an addition to one's personal anesthesia library. 